\title{
Placental tissues as sources of stem cells-Review
}

\author{
Renata Avancini Fernandes, Carolina Costola-Souza, Carlos Alberto Palmeira Sarmento, \\ Leandro Gonçalves, Phelipe Oliveira Favaron, Maria Angelica Miglino*
}

Faculty of Veterinary Medicine and Animal Science, University of Sao Paulo, Sao Paulo, Brazil;

*Corresponding Author: miglino@usp.br

Received 14 May 2012; revised 17 June 2012; accepted 29 June 2012

\section{ABSTRACT}

Recently the fetal membranes are regarded to be abundant, ethically acceptable and easily accessible sources of mesenchymal stem cells, which cause only minor immunogenic troubles. In addition, these membranes have been studied as an alternative to adult and embryonic stem cells. The chorion develops firstly as a layer of simple avascular epithelium (trophoblast). The amnion, as the chorion is also an avascular membrane. It is derived from the ectoderm, and forms a very thin membrane which surrounded the embryo in development. The hypoblast and exocoelomic membrane together originates the yolk sac which late will give rise to the allantois. The study of the origin and development of these tissues is of vital importance for obtaining stem cells. Different cell lineages can be obtained from the fetal placental tissues: the hematopoietic lineage is found in the chorion, allantois and, yolk sac, and the mesenchymal lineage is found in the chorion and amnion. The properties and potential for differentiation of fetal stem cells isolated from placental tissues must be characterized in order for them to be used in the treatment of several diseases. The chorion, yolk sac, allantois, and amnion contain heterogeneous cell populations. However, few studies have focused on characterizing these alternative stem cells sources. The amnion has a significant advantage over the other fetal membranes, mainly due to its easily accessibility for collection in humans and rodents and also because it contains populations of pluripotent and multipotent cells. In some other species (dogs, ruminants, horses, cats, and swine) the allantoic fluid is more easily accessible, but there is little information regarding the characterization of the cell population. This review will address advances in the isolation of stem cells from fetal placental tissues and describe their characteri- zation and possible use in cell therapy, as well as their origin and development.

Keywords: Amnion; Allantois; Yolk Sac; Chorion; Stem Cells

\section{INTRODUCTION}

\subsection{Development of the Placental, Embryonic and Fetal Tissues}

The fusion of a male and female gamete results in a zygote. During repeated cell divisions, the zygote develops progressively into a blastocyst, an embryo, and upon organ differentiation, into a fetus. In viviparous vertebrates, the embryo develops extra-embryonic membranes which showed several and important functions during the embryo and fetal life. However, during this period, physiological exchange processes, such as respiration and nutrition, require special provisions [1]. These functions are provided by an intimate connection between parts of the fetal membranes and the endometrium, which is followed by the implantation process. The combined organ formed from this process, the placenta, consists of a fetal component and the modified uterine wall [2]. The fetus and the fetal placenta together form the conceptus. The development and joining of the fetal membranes to the uterine epithelium result in the development of the placenta, i.e. placentation [3]. In this way, in all those places that these fetal membranes are apposed or even fusing with the uterine mucosa for the purpose of maternalfetal exchange a placenta is formed [3] (Figure 1).

The blastocyst wall is composed of a unilaminar epithelium, called the trophoblast, which develops before the inner cell mass differentiates into germ layers. A layer of mesoderm is then added and the composite membrane is known as the chorion. An ectodermal vesicle also lined with mesoderm, the amnion, surrounds the embryo and sustains it in liquid. An endodermal vesicle, the yolk sac, which is in communication with the posterior intestine, the allantois, participates in the formation 
of the placenta as well. The mesoderm of the chorion and amnion is part of the extraembryonic somatopleure, while the mesoderm of the yolk sac and allantois originates from the extraembryonic splanchnopleure [4].

The chorion develops first as a single layer of avascular epithelium, the trophoblast. Growth of the leafy chorion results in the vast increase in the contact area between the trophoblast and the endometrial tissue [4].

The allantois is a small diverticulum that originates from the posterior wall of the yolk sac after the appearance of the cloacal membrane [5]. It is thought that the allantois guides the formation of umbilical vessels. In mammals, it takes on respiratory function and storage of excreted materials [6]. Allantoic vasculogenesis begin from the distal tip of the allantois, which contains mesoderm, and progresses in two directions: distally to fuse with the chorion and form the placental labyrinth, and proximally to connect with the dorsal aorta [7].

Amniogenesis is the result of the gradual displacement of epiblast cells toward the embryonic pole by the accumulation of fluids, where they differentiate into a thin amniotic membrane that separates the new cavity from cytotrophoblast, resulting in formation of the amniotic cavity. After a few weeks, the amniotic cavity surrounds the entire embryo. Thus, the amniotic cavity is covered by amnioblasts and sits on epiblast [6]. The amniotic membrane is a tissue of fetal origin and is composed of three layers: a layer of simple epithelium, a thick basal membrane and an avascular mesenchyme [8]. This membrane receives oxygen and nutrition from the chorionic fluid, the amniotic fluid and surface fetal ves- sels [9].

The vitelline cavity is the first of the embryonic annexes to form. In birds, it is formed just before the amniotic cavity. In placental mammals, unlike monotremes, it undergoes atrophy during embryonic development. A cavity lined with hypoblast and flattened cells forms first, probably originating from mesodermal differentiation of the cytotrophoblast. During embryonic development, the hypoblast develops to completely line the previously formed primitive vitelline cavity. Then, having already differentiated into an endoblast, it fully delimits the secondary vitelline cavity [10].

Placental tissues may harbor cells that show plasticity, which is characteristic of pre-gastrulation embryonic cells, and which have the potential to differentiate into different lineages. This notion is well supported by the fact that these tissues are generated during embryonic development, always before the onset of gastrulation [11]. The human placenta is an alternative source of mesenchymal stem cells that bypass the limitations of other sources such as bone marrow, umbilical cord, peripheral blood and adipose tissue. Mesenchymal stem cells from these sources are promising [12], but in some cases are limited in terms of accessibility and utility [13,14].

Studies by [15] showed that mesenchymal stem cells are present in the human placenta. Using routine cell culture techniques, placental mesenchymal stem cells can be successfully isolated and expanded in vitro. Although the starter culture consists of fibroblastoid and non-fibroblastoid cell types, only the fibroblastoid population remains after enzymatic digestion and passages.

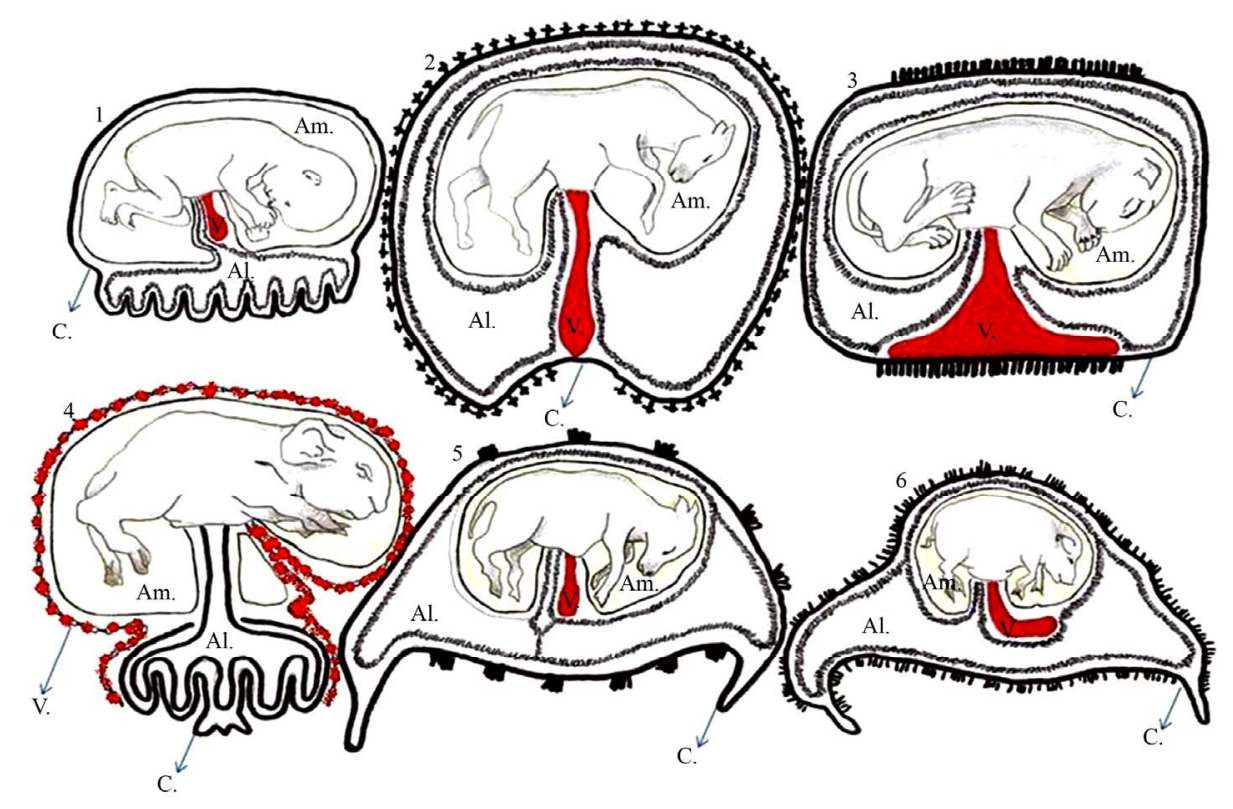

Figure 1. Schematic representation of the different types of placenta in various domestic species. 1: Human placenta; 2: Equine; 3: Feline; 4: Rodent; 5: Ruminant; 6: Swine. Am = amnion, $\mathrm{Al}=$ allantois, V: yolk sac, and C: chorion. Adapted from Leiser and Kaufmann (1994). 


\subsection{Stem Cells Derived from the Chorion and Allantois}

As described in the literature cells isolated from the chorionic membrane showed only mesenchymal properties [16]. The isolation of mesenchymal cells can be performed by culture of fetal chorionic villi explants, although this entails a high risk of maternal contamination [17-19]. Another technique used for isolation of mesenchymal cells from human chorion is dispase and collagenase treatment $[18,20]$. Recent studies suggest that stromal mesenchymal cells derived from human chorion (SMCHCs) isolated in the first trimester proliferate better than cells obtained in the third gestation trimester [20].

Overall, the ultrastructural characteristics of SMCHCs resemble those of hematopoietic progenitors and tumors of small round blue cells (e.g., Ewing sarcoma), suggesting they are positioned at the highest level of the stem cell hierarchy [16]. The profile of surface markers in cultured human mesenchymal stromal cells from the amnion and chorion is similar to that of mesenchymal stromal cells from adult bone marrow. They all express typical mesenchymal markers but are negative for hematopoietic markers (CD34 and CD45) and monocytic markers (CD14) [18,20,21]. SMCHCs differentiate into classical mesoderm lineages (osteogenic, chondrogenic and adipogenic) [18,20,21] demonstrated their capacity for myogenic (MyoD1+) and neurogenic (CD133+) differentiation. In vivo tests showed that human chorionic cells persisted successfully in grafts in multiple organs, as they were detected in the brain, lung, bone marrow, thymus, spleen, kidney and liver after intraperitoneal or intravenous transplantation in neonatal swine and mice. This finding was indicative of active migration and molecule adhesion [22].

The pre-fusion allantois and chorion are good sources of hematopoietic progenitor cells. Prior to fusion, cells express CD41, a marker for early hematopoiesis [23], and also give rise to definitive myeloid and erythroid lineages in culture [24]. Two morphologically distinct cell populations are established in the allantois [25] and [26]: an outer layer of "mesothelium", and an inner core of vascularized mesoderm, defined initially by a plexus of endothelial cells. The early appearance of hematopoietic stem cells in the placenta suggests that the allantoic mesoderm and its derivatives may be involved in the generation of hematopoietic stem cells and/or maturation of these cells in adults [27]. Suzuki and Nakano [28] analyzed the hematopoietic potential of the chorion and allantois. They isolated these tissues before the conceptus established a connection with the circulatory system, first culturing explants of the allantois and chorion on a layer of Op9 stromal cells in the presence of hematopoietic cytokines that support the growth and differentiation of cells in the myeloid lineage (IL3, IL6, G-CSF, GM-CSF).
Both the allantois and chorion from the conceptus gave rise to many non-adherent, round cells as efficient as those seen in paraaortic splanchnopleura, demonstrating the presence of a hematopoietic stem cell environment.

\subsection{Stem Cells Derived from the Amnion}

It is expected that the amniotic membrane can maintain pluripotent potential for differentiation. During development, the inner cell mass of the blastocyst, from which embryonic stem cells are derived, gives rise to the epiblast (from which the embryo is obtained) and hypoblast (from which the yolk sac is derived). The epithelial layer of amniotic membrane (amniotic ectoderm) is obtained from the epiblast (embryonic ectoderm), whereas the mesenchymal cells (amniotic mesenchyme) are derived from the primitive lineage of extra-embryonic mesoderm [29]. Amniotic epithelial cells are thought to possess the capacity to originate the three germ layers, since the epiblast develops into all the germ layers of the embryo. Furthermore, the epithelial layer of the amniotic membrane originates before gastrulation, i.e., before cellular differentiation and specification. Thus, amniotic epithelial cells are expected to retain the plasticity of the pregastrulation cells of the embryo [30].

Int'Anker et al. [21] found that the growth curve of mesenchymal stem cells obtained from amniotic fluid and the amniotic membrane were similar. Based on this data, they hypothesized that mesenchymal stem cells derived from amniotic fluid are at least in part derived from the amnion. They also analyzed amniotic fluid from the second and third trimester of human gestation and confirmed that both are rich in mesenchymal stem cells. Moreover, these cells showed a significantly greater potential for expansion compared to mesenchymal stem cells isolated from adult bone marrow.

The human amnion can be easily obtained from a placenta at birth and thus carries no ethical problems related to its use. Previous studies have demonstrated the capacity of differentiation of mesenchymal cells derived from human amniotic fluid in osteogenic, adipogenic and chondrogenic lineages [31]. The in vivo therapeutic potential of mesenchymal cells derived from human amnion is already being investigated [32]. Furthermore, stem cells from amniotic fluid express Oct-4, a specific marker of pluripotent stem cells, and also exhibit high proliferative and differentiation capacity [33].

A specific cellular subpopulation of morphologically distinct cells was mechanically isolated and selectively expanded from amniotic fluid of pregnant sheep, and the immunocytochemical profiles of many specific cell subpopulations were determined, in addition to the following cell lineages: mesenchymal, fibroblast/myofibroblast. Expression of vimentin, smooth muscle actin, cytokeratins 8 and 18, and fibroblast surface protein were 
detected, but the cells were negative for desmin and CD31. They also had significantly faster proliferation rates than fetal and adult cells [34].

\subsection{Stem Cells Derived from the Yolk Sac}

In rodents, the yolk sac is structurally diverse showing different cell types (Figure 2) which shows several important functions during embryonic development, e.g. the yolk sac is responsible for the development of the vascular system [35-37] primordial germ cells migrate to the developing gonad [38]; and contributes to form the midgut [38]. In addition, the endodermal cells promote maternal-fetal exchange [39]. Normal embryonic development is highly dependent on the proper functioning of the yolk sac for transport through the endodermal layer, metabolization of maternal macromolecules and synthesis of serum proteins, and as the layer of mesoderm that produces the first blood cells within blood islands [40]. All different types of blood cells are derived from hematopoietic stem cells, which largely represent a quiescent population that demonstrates self-renewal [41].

The main sites of hematopoiesis change in time and space during human development. Blood cells arise initially in the yolk sac, followed sequentially by fetal liver and finally, the development in long bones [43,44]. As in the mouse, the human yolk sac gives rise to primitive erythrocytes and macrophages [41]. The yolk sac can also repopulate the newly formed recipients, contributing to hematopoiesis in normal adult development [42]. However, the role of the yolk sac in the biology of hematopoietic stem cells remains partially unclear.

Due these several important functions during the em- bryo development and organogenesis, the yolk sac may be a promising source of progenitor stem cells as had been shown for instance for some laboratorial species and human.

Wenceslau et al. [45] described that the canine yolk sac after culture was able to differentiate in bone and cartilage. In addition, the authors suggested that these mesenchymal progenitor cells could be an appropriate in vitro model to study mesenchymal progenitor cells biology to understand the hematopoietic territories that support the fetal hematopoiesis.

During the embryonic stage, mesenchymal progenitor cells isolated from human yolk sac were able to express not only mesenchymal stem cells markers, but also pluripotent stem cells markers as Oct3/4 and Nanog. After treatment with specific mediums these mesenchymal progenitor cells were able to differentiate into only bone and adipose cells [46].

The Figure 3 show in detail the different cells types that can be obtained from the amnion, chorion, yolk sac, and allantois.

\subsection{Therapeutic Application}

Recently, human mesenchymal amniocytes showed to be able to be expanded ex vivo in the absence of animal serum while maintaining the progenitor phenotype. This property is a prerequisite for regulatory compliance with the requirements for human clinical testing [47]. The presence of human nuclei (NH-positive cells) in the striatum was identified in all normal and ischemic mice 10, 30 and 90 days after transplantation of mesenchymal stem cells derived from human amniotic fluid, indicating
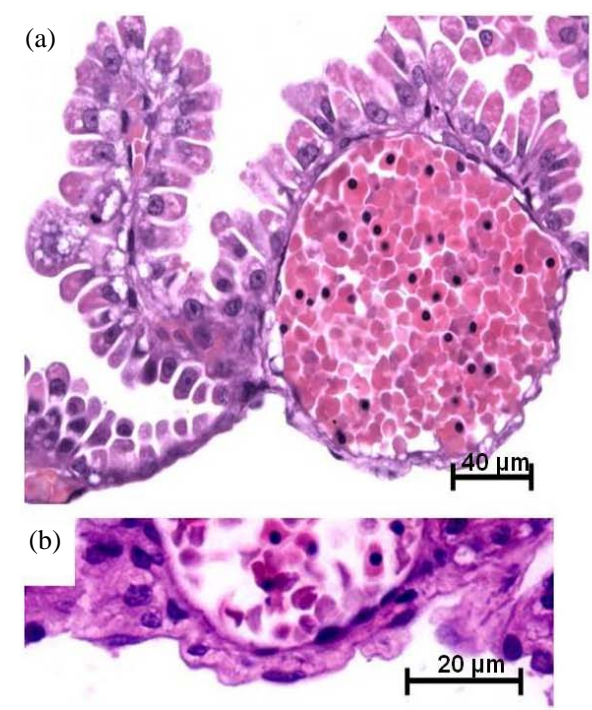

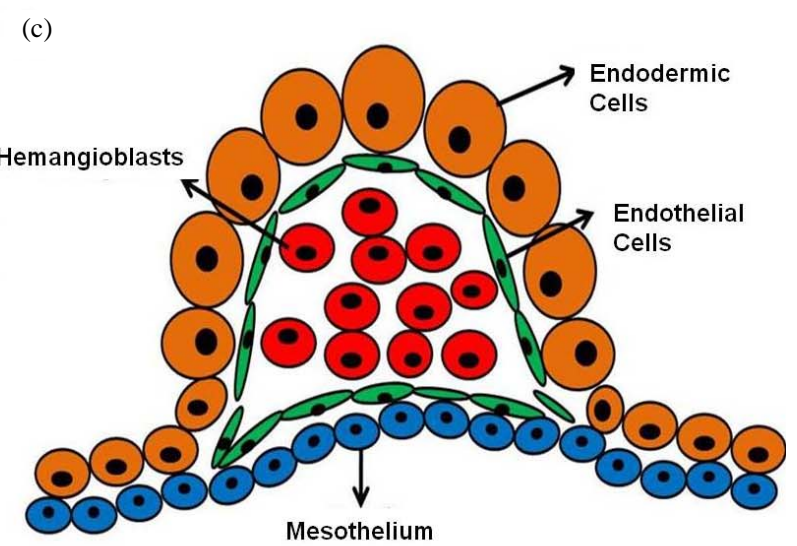

Mesothelium

Figure 2. Histology and squematic view of the structural characteristics of the yolk sac and vascular islands in a rodent specie from South America, i.e. Necromys lasiurus (Rodentia, Cricetidae). In (a) and (b) details of the endodermic cells, mesothelium, endothelial cells, and hemangioblasts; (c) squematic view. Stained using: Hematoxylin and eosin. 


\begin{tabular}{|c|c|c|}
\hline Tissue & Stem Cells & Differentiation \\
\hline Chorion & mesenchymal & $\begin{array}{l}\text { Osteoblasts, chondrocytes, adipocytes, } \\
\text { cardiac myocytes, fibroblasts, } \\
\text { myofibroblasts, pericytes, skeletal } \\
\text { myocytes, tenocytes, retinal cells, } \\
\text { neurons, astrocytes, hepatocytes, } \\
\text { stromal hematopoietic support, } \\
\text { pancreatic cells. }\end{array}$ \\
\hline $\begin{array}{l}\text { Yolk sac } \\
\text { Allantois }\end{array}$ & hematopoietic & $\begin{array}{l}\text { Erythrocytes } \\
\text { Leukocytes }\end{array}$ \\
\hline Chorion & & \\
\hline
\end{tabular}

Figure 3. Possible differentiation of stem cells from fetal placental tissues. Adapted from Pountos and Giannoudis (2005).

that these cells could survive for a long time in a new microenvironment. The NH-positive cells were found at all injection sites, in a dense deposit around the transplantation site in 10 days and more diluted at 30 and 90 days. In normal animals, the migrated cells were distributed in several regions, including the septum, corpus callosum and cerebral cortex. In contrast, in ischemic brains, NH-positive cells were seen in the striatum adjacent to or near the corpus callosum, while most of the transplanted cells were found migrating to the border of the ischemic lesion [48].

Fuchs et al. [49] examined sheep amniocyte grafts (marked with GFP) in diaphragmatic reconstruction of sheep neonates, versus a control group in which the reconstruction was done without the addition of amniocytes. Few cells were observed by histology in the acellular grafts. High cellularity and higher organization was observed in the cellular implants, where each GFP-positive cell was more obviously aligned parallel to the collagen fibers. Another study of sheep amniocytes used the transplantation of amniocytes after chondrogenic differentiation in the treatment of tracheal repair in newborn lambs. Of the seven treated animals, five survived, and in these, the histological findings showed a line of pseudostratified epithelium and fibrous cartilage, causing tracheal reconstruction. From these results, the authors concluded that grafts derived from mesenchymal amniocytes may be a viable alternative in tracheal repair [47, 50].

\section{FINAL CONSIDERATIONS}

The ease of isolation of the different fetal placental tissues (the chorion, allantoic, amniotic and yolk sac), varies according to the species, as shown in Figure 1. Although some of these tissues are difficult to access, they are currently all available in each species. The ease in obtaining these tissues is closely related to placental location and layout, where the higher the proximity of the attachment to the uterus, the easier the access. In dogs, cats, equines, ruminants and swine, the easiest tissue to access is the allantois, because it is more external to the conceptus, whereas in humans and rodents the amniotic is most readily obtained.

Once these tissues are collected, stem cells can be isolated. From the chorion, allantois, amniotic and yolk sac, we can isolate both mesenchymal and/or hematopoietic cell lineages. Pasquinelli et al. [16] reported that cells isolated from the chorion have exclusively mesenchymal properties. Int'Anker et al. [21], Portman et al. [20] and Soncini et al. [18] confirm these studies, showing that the isolated cells expressed typical mesenchymal markers and were negative for CD34 and CD45 hematopoietic markers. These studies also showed that these cells could differentiate into osteogenic, chondrogenic and adipogenic lineages. In contrast, [23] found that chorion-derived stem cells, expressed hematopoietic markers, such as CD41, prior to fusion of the allantois. However, [51] reported that these cells can generate myeloid and erythroid lineages in culture. Thus, we conclude that cells isolated from the chorion have both mesenchymal and hematopoietic properties, and therefore these tissues are good sources of cells of hematopoietic and mesenchymal lineages.

The allantois has hematopoietic characteristics and is usually studied along with the chorion, since the focus of such studies are rodents that serve as placental models for humans, in which these two tissues fuse in the 
chorioallantoic placenta. The hematopoietic properties of the chorion are also seen in the allantois, whereas mesenchymal properties have to date only been observed in the chorion.

The yolk sac, present in all domestic animals and in humans, differs in size and development among the species. However, it is generally largest in early gestation, since it is responsible for the development of the blood cells. According to [42] the yolk sac gives rise to immature hematopoietic stem cells. There are also differences between the embryonic annexes, as primitive lineages of many cell types could be easily obtained.

The amnion, which is present in large quantities in humans, is routinely used for prenatal diagnosis of genetic diseases. Thus, we can use the amnion for collection and isolation of stem cells that have mesenchymal properties. The amnion is a good source of stem cells because its epithelial layer originates before gastrulation [52], and is therefore thought to retain pluripotent properties [53]. As gastrulation is important in differentiation and specification of cell fate, it is expected that the cells retain plasticity before gastrulation [30]. Int'Anker et al. [21] showed that cells from amniotic fluid and membrane have similar characteristics. Kim et al. [31] showed that these cells could be differentiated into osteogenic, adipogenic and chondrogenic lineages. Siegel further confirmed that amnion cells express Oct-4, a marker of pluripotent cells, as shown by [53]. Thus, we can use the material that is most easily accessible according to gestation time, puncture amniotic fluid (amniocentesis) during gestation and the conceptus membrane at birth, without the need for surgical intervention. The amnion is the most well studied fetal membrane because it has the greatest volume and is most easily accessible in humans. Furthermore, the heterologous transplantation of human amniocytes into animals is a major advance in medicine today, and so far, these injected cells are not rejected by the body, do not form tumors, and are found among the other cells.

Fetal stem cells are more primitive than adult stem cells, which gives them a greater capacity for differentiation, but more developed than embryonic cells, which reduced the risk of tumors. Moreover, obtaining fetal placental tissues does not carry significant ethical problems. Consequently, these cells are becoming more widely studied, and current research indicates that fetal stem cell therapy will be an accurate and effective treatment strategy in the near future.

\section{ACKNOWLEDGEMENTS}

We would like to thank the several members of the Faculty of Veterinary Medicine and Animal Science, University of Sao Paulo, Brazil and also the Fundação de Amparo à Pesquisa do Estado de São Paulo
—Fapesp for financial support.

\section{REFERENCES}

[1] Mossman, H.W. (1987) Vertebrate fetal membranes: Comparative ontogeny and morphology; evolution; phylogenetic significance: Basic functions; research opportunities. The Mammalian Press, London.

[2] Enders, A.C. and Welsh, A.O. (1993) Structural interactions of trophoblast and uterus during hemochorial placenta formation. Journal Experimental Zoology, 266, 578-587.

[3] Leiser, R. and Kaufmann, P. (1994) Placental structure: In a comparative aspect. Experimental Clinical Endocrinology, 102, 122-134. doi: 0.1055/s-0029-1211275

[4] Björkman, N. (1982) Placentação. In: Dellman, H. and Broxn, E.M., Eds., Histologia Veterinária, Guanabara Koogan, Rio de Janeiro.

[5] Sadler, T.W. (2005) Langman embriologia médica. Guanabara Koogan, Rio de Janeiro.

[6] Garcia, S.M.L. and Fernández, C.G. (2001) Embriologia. Editora Artmed, Porto Alegre.

[7] Downs, K.M, Hellman, E.R., McHugh, J., Barrickman, K. and Inman, K.E. (2004) Investigation into a role for the primitive streak in development of the murine allantois. Development, 131, 37-55. doi:10.1242/dev.00906

[8] Benirschke K. and Kaufman P. (2000) Pathology of the human placenta. Springer-Verlag, New York.

[9] Mess, A.M. and Ferner, K.J. (2010) Evolution and development of gas exchange structures in Mammalia: The placenta and lung. Respiratory Physiology and Neurobiology, 173, 74-82. doi:10.1016/j.resp.2010.01.005

[10] Almeida, J.M. (1999) Embriologia veterinária veterinária. Guanabara Koogan, Rio de Janeiro.

[11] Evangelista, M., Soncini M. and Parolini, O. (2008) Placenta-derived stem cells: New hope for cell therapy? $\mathrm{Ci}$ totechnology, 58, 33-42. doi: 10.1007/s10616-008-9162-z

[12] Chen, Y., Shao, J.Z., Xiang, L.X., Dong, X.J. and Zhang, G.R. (2008) Mesenchymal stem cells: A promising candidate in regenerative medicine. The International Journal of Biochemistry \& Cell Biology, 40, 815-820. doi:10.1016/j.biocel.2008.01.007

[13] Minguell, J.J., Erices, A. (2006) Mesenchymal stem cells and the treatment of cardiac disease. Experimental Biology and Medicine, 231, 39-49. doi:1535-3702/06/2311-0039

[14] Villaron, E.M., Almeida, J., López-Holgado, N., Alcoceba, M., Sánchez-Abarca, L.I., Sanchez-Guijo, F.M., Alberca, M., Pérez-Simon, J.A., San Miguel, J.F. and Del Cañizo, M.C. (2004) Mesenchymal stem cells are present in peripheral blood and can engraft after allogenic haematopoietic stem cell transplantation. Haematologia, 89, 14211427.

[15] Miao, Z., Jin, J., Chen, L., Zhu, J., Huang, W., Zhao, J., Qian, H. and Zhang, X. (2006) Isolation of mesenchymal stem cell from human placenta: Comparison with human 
bone marrow mesenchymal stem cells. Cell Biology International, 30, 681-687. doi:10.1016/j.cellbi.2006.03.009

[16] Pasquinelli, G., Tazzari, P., Ricci, F., Vaselli, C., Buzzi, M., Conte, R., Orrico, R., Foroni, L., Stella, L., Alviano, F., Bagnara, G.P. and Lucarelli, E. (2007) Ultrastructural characteristics of human mesenchymal stromal (stem) cells derived from bone marrow and term placenta. Ultrastructural Pathology, 31, 23-31. doi:10.1080/01913120601169477

[17] Zhang, X., Mitsuru, A., Igura, K., Takahashi, K., Ichinose, S., Yamaguchi, S. and Takahashi, T.A. (2006) Mesenchymal progenitor cells derived from chorionic villi of human placenta for cartilage tissue engineering. Biochemical and Biophysical Research Communications, 340, 944-952. doi:10.1016/j.bbrc.2005.12.091

[18] Soncini, M., Vertua, E., Gibelli, L., Zorzi, F., Denegri, M., Albertini, A., Wengler, G.S. and Parolini, O. (2007) Isolation and characterization of mesenchymal cells from human fetal membranes. Journal of Tissue Engineering and Regenerative Medicine, 1, 296-305. doi:10.1002/term.40

[19] Zhang, X., Soda, Y., Takahashi, K., Bay, Y., Mitsuru, A., Igura, K., Satoh, H., Yamaguchi, S., Tani, K., Toko, A. and Takahashi, T.A. (2006) Successful immortalization of mesenchymal progenitor cells derived from human placenta and the differentiation abilities of immortalized cells. Biochemical and Biophysical Research Communication, 351, 853-859. doi:10.1016/j.bbrc.2006.10.125

[20] Portmann-Lanz, C.B., Schoeberlein, A., Huber, A., Sager, R., Malek, A., Holzgreve, W. and Surbek, D.V. (2006) Placental mesenchymal stem cells as potential autologous graft for pre- and perinatal neuroregeneration. American Journal of Obstetrics and Gynecology, 194, 664-673. doi:10.1016/j.ajog.2006.01.101

[21] In’tAnker, P.S., Scherjon, S.A., Kleijburg-van der Keur, C., de Groot-Swings, G.M., Claas, F.H., Fibbe, W.E. and Kanhai, H.H. (2004) Isolation of mesenchymal stem cells of fetal or maternal origin from human placenta. Stem Cells, 22, 1338-1345. doi:10.1634/stemcells.2004-0058

[22] Bailo, M., Soncini, M., Vertua, E., Signoroni, P.B., Sanzone, S., Lombardi, G., Arienti, D., Calamani, F., Zatti, D., Paul, P., Albertini, A., Zorzi, F., Cavagnini, A., Candotti, F., Wengler, G.S. and Parolini, O. (2004) Engraftment potential of human amnion and chorion cells derived from term placenta. Transplantation, 78, 1439-1448.

[23] Corbel, C., Salaun, J., Belo-Diabangouaya, P. and Dieterlen-Lièvre, F. (2007) Hematopoietic potential of the prefusion allantois. Developmental Biology, 301, 478-488. doi:10.1016/j.ydbio.2006.08.069

[24] Zeigler, B.M., Sugiyama, D., Chen, M., Guo, Y., Downs, K.M. and Speck, N.A. (2006) The allantois and chorion, when isolated before circulation or chorio-allantoic fusion, have hematopoietic potential. Development, 133, 41834192. doi:10.1242/dev.02596

[25] Ellington, S.K.L. (1985) A morphological study of the development of the allantois of rat embryos in vivo. Journal of Anatomy, 142, 1-11.

[26] Downs, K.M., Gifford, S., Blahnik, M. and Gardner, R.L.
(1998) The murine allantois undergoes vasculogenesis that is not accompanied by erythropoiesis. Development, 125, 4507-4521.

[27] Gekas, C., Dieterlen-Lievre, F., Orkin, S.H. and Mikkola, H.K.A. (2005) The placenta is a niche for hematopoietic stem cells. Developmental Cell, 8, 365-375. doi: 10.1016/j.devcel.2004.12.016

[28] Suzuki, A. and Nakano, T. (2001) Development of hematopoietic cells from embryonic stem cells. International Journal of Hematology, 73, 1-5. doi: 10.1007/BF02981896

[29] Enders, A.C. and King, B.F. (1988) Formation and differentiation of extraembryonic mesoderm in the rhesus monkey. American Journal of Anatomy, 181, 327-340. doi:10.1002/aja.1001810402

[30] Miki, T., Lehmann, T., Cai, H., Stolz, D.B. and Strom, S.C. (2005) Stem cells characteristics of amniotic ephitelial cells. Stem Cells, 23, 1549-1559. doi:10.1634/stemcells.2004-0357

[31] Kim, J., Lee, Y., Hwang, K.J., Kwon, H.C., Kim, S.K., Cho, D.J., Kang, S.G. and You, J. (2007) Human amniotic fluid-derived stem cells have characteristics of multipotent stem cells. Cell Proliferation, 40, 75-90. doi:10.1111/j.1365-2184.2007.00414.X

[32] Han, K., Lee, J.E., Kwon, S.J., Park, S.Y., Shim, S.H., Kim, H., Moon, J.H., Suh, C.S. and Lim, H.J. (2008) Human amnion-derived mesenchymal stem cells are a potential source for uterine stem cell therapy. Cell Proliferation, 4, 1709-1725. doi:10.1111/j.1365-2184.2008.00553.x

[33] Siegel, N., Rosner, M., Hanneder, M., Valli, A. and Hengstschläger, M. (2007) Stem cells in amniotic fluid as new tools to study human genetic diseases. Stem Cell Reviews, 3, 256-264. doi: 10.1007/s12015-007-9003-z

[34] Kaviani, A., Perry, T.E., Dzakovic, A., Jennings, R.W., Ziegler, M.M. and Fauza, D.O. (2001) The amniotic fluid as a source of cells for fetal tissue engineering. Journal of Pediatric Surgery, 36, 1662-1665. doi:10.1053/jpsu.2001.27945

[35] Auerbach, R., Huang, H. and Lu, L. (1996) Hematopoietic stem cells in the mouse embryonic yolk sac. Stem Cells, 14, 269-280. doi:10.1002/stem.140269

[36] Medvinsky, A.L., Samoylina, N.L., Müller, A.M. and Dzierzak, E.A. (1993) An early pre-liver intraembryonic source of CFU-S in the developing mouse. Nature, 364, 64-67. doi:10.1038/364064a0

[37] Jafredo, T., Bollerot, K., Sugiyama, D.G. and Drevon, C. (2005) Tracing the hemangioblast during embryogenesis: developmental relationships between endothelial and hematopoietic cells. International Journal of Developmental Biology, 49, 269-277. doi: 10.1387/ijdb.041948tj

[38] Hyttel, P., Sinowatz, F. and Vejlsted, M. (2010) Essentials of domestic animal embryology. Saunders Elsevier, Toronto.

[39] Favaron, P.O., Carter, A.M., Mess, A.M., de Oliveira, M.F. and Miglino, M.A. (2012) An unusual feature of yolk sac placentation in Necromys lasiurus (Rodentia, Cricetidae, Sigmodontinae) Placenta, 33, 578-580. 
doi:10.1016/j.placenta.2012.02.011

[40] Jollie, W.P. (1990) Development, morphology, and function of the yolk-sac placenta of laboratory rodents. Teratology, 41, 361-381. doi:10.1002/tera.1420410403

[41] Palis, J. and Yoder, M.C. (2001) Yolk-sac hematopoiesis: The first blood cells of mouse and man. Experimental Hematology, 29, 927-936. doi:10.1016/S0301-472X(01)00669-5

[42] Mikkola, H.K.A., Gekas, C., Orkin, S.H. and DieterlenLievre, F. (2005) Placenta as a site for hematopoietic stem cell development. Experimental Hematology, 33, 1048-1054. doi:10.1016/j.exphem.2005.06.011

[43] Kelemen, E. and Calvo, W. (1979) Atlas of human hematopoietic development. Springer-Verlag, New York.

[44] Charbord, P., Tavian, M., Humeau, L. and Péault, B. (1996) Early ontogeny of the human marrow from long bones: An immunohistochemical study of hematopoiesis and its microenvironment. Blood, 87, 4109-4119.

[45] Wenceslau, C.V., Miglino, M.A., Martins, D.S., Ambrósio, C.E., Lizier, N.F., Pignatari, G.C. and Kerkis, I. (2011) Mesenchymal progenitor cells from canine fetal tissues: yolk sac, liver, and bone marrow. Tissue Engineering: Part A, 17, 2165-2176. doi:10.1089/ten.tea.2010.0678

[46] Wang, X.Y., Lan, Y., He, W.Y., Zhang, L., Yao, H.Y., Hou, C.M., Jong, Y., Liu, Y.L., Yang, G., Liu, X.D., Yang, X., Liu, B. and Mao, N. (2008) Identification of mesenchymal stem cells in aorta-gonad-mesonephros and yolk sac of human embryos. Blood, 111, 2436-2443. doi:10.1182/blood-2007-07-099333

[47] Kunisaki, S.M., Armant, M., Kao, G.S., Stevenson, K., Kim, H. and Fauza, D.O. (2007) Tissue engineering from human mesenchymal amniocytes: A prelude to clinical trials. Journal of Pediatric Surgery, 42, 974-980. doi: 10.1016/j.jpedsurg.2007.01.031

[48] Cipriani, S., Bonini, D., Marchina, E., Balgkouranidou, I., Caimi, L., Zucconi G.G. and Barlati, S. (2007) Mesenchymal cells from human amniotic fluid survive and migrate after transplantation into adult rat brain. Cell Biology International, 31, 845-850. doi:10.1016/j.cellbi.2007.01.037

[49] Fuchs, J.R., Kaviani, A., Oh, J.T., Lavan, D., Udagawa, T., Jennings, R.W., Wilson, J.M. and Fauza, D.O. (2004) Diaphragmatic reconstruction with autologous tendon engineered from mesenchymal amniocytes. Journal of Pediatric Surgery, 39, 834-838. doi:10.1016/j.jpedsurg.2004.02.014

[50] Kunisaki, S.M., Chang, R.W., Andreoli, S., Lewicke, S., Peña-Peterson, S., Jennings, R.W. and Fauza, D.O. (2006) Hyperoncotic enhancement of fetal pulmonary growth after tracheal occlusion: An alveolar and capillary morphometric analysis. Journal of Pediatric Surgery, 41, 34-39. doi:10.1016/j.jpedsurg.2006.03.001

[51] Zeigler, B.M., Sugiyama, D., Chen, M., Guo, Y., Downs, K.M. and Speck, N.A. (2006) The allantois and chorion, when isolated before circulation or chorio-allantoic fusion, have hematopoietic potential. Development, 133, 41834192. doi:10.1242/dev.02596

[52] Diwan, S.B. and Stevens L.C. (1976) Development of teratomas from the ectoderm of mouse egg cylinders. Journal of National Cancer Institute, 57, 937-942. doi: 10.1093/jnci/57.4.937

[53] Enders, A.C. and King, B.F. (1988) Formation and differentiation of extraembryonic mesoderm in the rhesus monkey. American Journal of Anatomy, 181, 327-340. doi:10.1002/aja.1001810402 